\title{
Pensando a educação musical imaginativamente: uma filosofia da educação musical por Estelle Ruth Jorgensen
}

\author{
Margarete Arroyo (UNESP, São Paulo, SP) \\ etearroyo@gmail.com.br
}

Resenha do livro JORGENSEN, Estelle R. Pictures of Music Education. Bloomington: Indiana University Press, 2011. 354 p. U\$29.95

Palavras-chave: metáfora e modelo em educação musical; filosofia da educação musical; Estelle R. Jorgensen.

Thinking music education imaginatively: a philosophy of music education by Estelle Ruth Jorgensen

Review of the book JORGENSEN, Estelle R. Pictures of Music Education. Bloomington: Indiana University Press, 2011. 354 p. U\$29.95

Keywords: metaphor and model in music education; philosophy of music education; Estelle R. Jorgensen.

Indagações sobre os valores da música e da educação musical têm sido feitas ao longo dos séculos na sociedade ocidental. Trata-se de questões de cunho filosófico que a partir do final da década de 1980 passaram a compor o recém-estabelecido campo da Filosofia da Educação Musical. A instituição dessa subárea dos estudos pedagógico-musicais ocorreu com ações decisivas de Estelle R. Jorgensen, autora do título aqui resenhado.

Jorgensen, australiana radicada nos Estados Unidos, participou intensamente da constituição da Filosofia da Educação Musical como "campo distinto de atividade profissional", liderando no início dos anos 1990 várias iniciativas: a criação do Grupo MENC Philosophy Special Research Interest; a realização da primeira Conferência em Filosofia da Educação Musical; a fundação da Sociedade Internacional de Filosofia da Educação Musical; e a publicação do periódico Philosophy of Music Education Review (MCCARTHY; GOBLE, 2011, s.p.). Sua vasta produção - artigos, organização e capítulo de livros, livros - desperta interesse de educadores musicais brasileiros em razão da presença marcante do pensamento de Paulo Freire ${ }^{1}$ como uma fundamentação recorrente nas reflexões da autora. Os livros, em número de quatro, articulam-se na construção de uma Filosofia da Educação Musical baseada no pensamento dialético ${ }^{2}$.

0 primeiro livro, "In search of Music Education" (JORGENSEN, 1997), apresenta a base filosófica sobre a qual constrói suas ideias e propostas para a Educação Musical. Entendo que a citação abaixo é central nesse volume bem como nas suas produções posteriores, pois expressa sua concepção de educação musical $\left.\right|^{3}$ :

A educação musical [...] é uma colagem de crenças e práticas. Seu papel na formação e manutenção dos [mundos musicais] - cada qual com seus valores, normas, crenças e expectativas implica formas diferentes nas quais ensino e aprendizagem são realizados. Compreender esta variedade sugere que pode haver inúmeras maneiras nas quais a educação pode ser conduzida com integridade. A busca por uma única teoria e prática de instrução musical aceita universalmente, pode levar a uma compreensão limitada (JORGENSEN, 1997, p.66). 
Em Transforming Music Education (JORGENSEN, 2003) a autora aborda mudanças necessárias à Educação Musical com base na atuação de músicos-educadores e de artistas. 0 terceiro livro, The Art of Teaching Music, de caráter prático, é "um convite para pensar, por meio de importantes aspectos, o que [educadores musicais] fazem e deveriam fazer" (JORGENSEN, 2008, p.xi).

A última publicação, Pictures of Music Education (JORGENSEN, 2011), compõe com as anteriores uma filosofia da educação musical sintetizada em quatro perspectivas articuladas: educação musical vista amplamente (JORGENSEN, 1997); educação musical vista transformativamente (JORGENSEN, 2003); educação musical vista como prática artesã (artful) (JORGENSEN, 2008); e educação musical vista imaginativamente (JORGENSEN, 2011). 0 termo "articulada" indica um trabalho de continuidade entre esses livros. A densidade do tratamento dos temas e $\mathrm{o}$ amadurecimento argumentativo tornam as ideias filosóficas de JORGENSEN sobre a Educação Musical material rico aos educadores musicais, estejam esses em situação de formação inicial, de atuação profissional, incluídos aqui os docentes formadores.

Pictures of Music Education está organizado em 14 capitulos, sendo o primeiro de cunho teórico e metodológico e o último conclusivo. Os capítulos intermediários ( 2 a 13) trazem, cada qual, um par de metáfora-modelo para a Educação Musical, material que compõe quadros imaginativos acerca desse campo de conhecimento e ação profissional ${ }^{4}$.

0 prefácio do livro inicia-se com uma série de perguntas relativas aos seus dois componentes-chave: metáfora e modelo.

Deveria a educação musical ser construida em termos metafóricos? Uma única metáfora seria capaz de fundamentar a educação musical? Se não, como avaliar as metáforas possiveis? Se as metáforas têm seu uso limitado, modelos poderiam constituir meios úteis para conceitualizar a educação musical? Se nem metáfora nem modelo seriam capazes de fundamentar a educação musical, poderia uma análise comparativa de metáfora e modelo ser útil? 0 que seria tal análise? Como as várias metáforas e modelos seriam avaliados criticamente bem como construtivamente para a educação musical? Qual seria a contribuição dessa análise para a prática da educação musical? (JORGENSEN, 2011, p.xi)

Pensar a Educação Musical a partir de metáforas surgiu do contado da filósofa com outros autores, mas mostrou-se insuficiente pela subjetividade acentuada. A "justaposição" desse elemento a outro mais objetivo - modelo [científico] - poderia conceder uma fundamentação mais consistente a essa Filosofia da Educação Musical, considerou Jorgensen. Além disso, a autora entende que, a despeito dos diálogos necessários que a Educação Musical tem mantido com outros campos de conhecimento, essa abordagem filosófica baseada na justaposição de metáfora e modelo possibilita um "exame sistemático" da educação musical sustentado "nas características e no trabalho da própria educação musical", isto é, possibilita pensá-la "músicoeducacionalmente" (music educationally).

Continuando a exposição dos argumentos que sustentam a recorrência às metáforas, Jorgensen lembra que o conhecimento artístico é também em grande parte imaginativo. Assim, empregar a metáfora para pensar a educação musical, "alinha-a com a música como empreendimento imaginativo, o que evidencia consistência entre 0 objeto estudado e a maneira de estudá-lo, iluminando potencialmente a educação musical" (JORGENSEN, 2011, p.2).

A comparação que faz entre "grandes narrativas" na Filosofia da Educação Musical - e aqui cita: Bennett Reimer, David Elliott, Thomas Regelski e Frede Nielsen que vislumbram um modelo ideal de educação musical e sua proposta filosófica que vai para outra direção, a "das inúmeras maneiras nas quais a educação pode ser conduzida com integridade" (JORGENSEN, 1997, p.66), esclarece mais acerca do pensar a educação musical metaforicamente:

As metáforas nos conduzem a uma direção muito diferente. Ao invés de tender a uma única e melhor maneira, aquela que abarcaria grandes narrativas [...] pensar metaforicamente sobre educação musical abre muitas possibilidades de conceber 0 trabalho da educação de modo a resistir a reduzi-lo a princípios universais. A opção por "muitos" ao invés de "um", com base no pensar metaforicamente, subverte a busca pelas "grandes narrativas", pelo "melhor e verdadeiro caminho" para a educação musical [...] (JORGENSEN, 2011, p.4).

Ressalta igualmente que essa perspectiva metafórica da educação musical

tem o potencial de problematizar a proeminência da maneira científica, objetiva e racional de pensar e agir. Enquanto os modelos são frequentemente testados de acordo com os cânones da ciência, as metáforas confiam na compreensão imaginativa e subjetiva que são mais suscetíveis à reflexão filosófica e à descrição qualitativa (JORGENSEN, 2011, p.3).

0 primeiro capítulo apresenta os argumentos de Jorgensen acerca dessa proposta e os procedimentos metodológicos empregados na elaboração da mesma. Nele, a autora justifica extensamente porque recorre a metáforas e a modelos. No caso da primeira, Jorgensen lembra que o discurso metafórico é recorrente tanto na própria pedagogia musical quanto na prática musical. São exemplos a fala de professores que se valem de metáforas para explicar acerca da música - emite esse som tão suavemente quanto um pluma deslizando no ar; ou de músicos - sons sombrios, etc. Desse modo a autora pergunta: "por que não levar essa forma de ação pedagógica e musical para pensar sobre a própria educação musical, de modo que abordagens usadas para explorar como as pessoas conhecem música sejam consistentes com a natureza da própria experiência musical?" (JORGENSEN, 2011, p.2). Pode-se depreender que essa argumentação sustenta a possibilidade de pensar a educação musical "músico-educacionalmente". 
Embora Jorgensen conceda à metáfora um lugar privilegiado na sua reflexão, reconhece que o pensamento científico também tem seu potencial, o que a move a considerar a "justaposição" entre metáfora e modelo.

Na distinção que a autora faz entre esses componentes, descreve metáfora como "um tipo de símbolo; algo que representa algo", mas não apenas na relação um a um. "Metáfora trabalha projetando ao assunto principal um sistema de 'implicações associadas' [...]", citando Max BLACK (1962, p.39). Ainda de acordo com esse autor, "a metáfora seleciona, enfatiza, suprime e organiza aspectos do assunto principal [...]" (JORGENSEN, 2011, p.5).

Na explicitação de "modelo" continua referenciada em BLACK. Jorgensen destaca que "modelos funcionam de modo similar à metáfora" no sentido de que "falar de modelo em conexão com uma teoria científica sugere uma metáfora". Entretanto, há diferença entre eles: enquanto a "metáfora opera com implicações de senso comum", o modelo "requer controle de teorias científicas firmemente construídas". A distinção entre metáfora e modelo para BLACK, cita Jorgensen, "é parcialmente uma questão de perspectiva histórica", pois a experiência pedagógico-musical pode iniciar-se de maneira imaginativa e subjetiva e tomar uma forma mais objetiva, mais sistemática. (JORGENSEN, 2011, p.5).

Procedimentos de ordem metodológica que compõem este capítulo estão indicados a seguir:

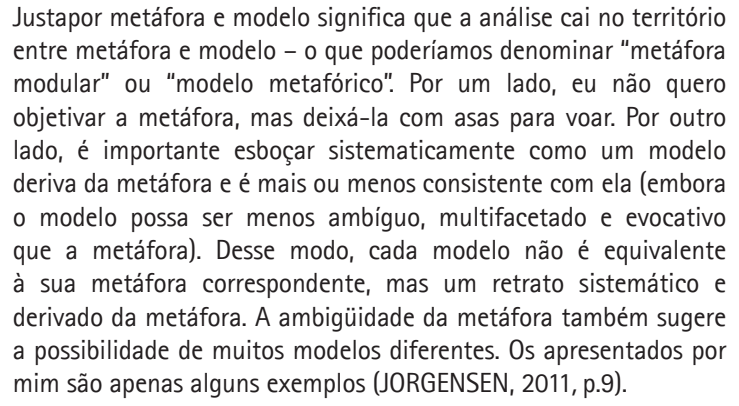
entre metáfora e modelo - o que poderiamos denominar "metáfora modular" ou "modelo metafórico". Por um lado, eu não quero objetivar a metáfora, mas deixá-la com asas para voar. Por outro lado, é importante esboçar sistematicamente como um modelo deriva da metáfora e é mais ou menos consistente com ela (embora o modelo possa ser menos ambíguo, multifacetado e evocativo que a metáfora). Desse modo, cada modelo não é equivalente à sua metáfora correspondente, mas um retrato sistemático e derivado da metáfora. A ambigüidade da metáfora também sugere a possibilidade de muitos modelos diferentes. Os apresentados por mim são apenas alguns exemplos (JORGENSEN, 2011, p.9).

A autora sugere que a educação musical é "tanto metáfora quanto modelo". Para sustentar tal perspectiva, vê-se diante de duas tarefas. A primeira "requer que cada metáfora seja construída de modo a evocar, ainda que em parte, o trabalho da educação musical [...]". Por exemplo: no capítulo 13, a metáfora é "Teia" [Web]. A segunda tarefa "demanda que as várias aparências de cada metáfora sejam sistematicamente consideradas em um modelo que deriva da metáfora" (JORGENSEN, 2011, p.9). No exemplo do capítulo 13, o modelo derivado da metáfora "Teia" é "Conectividade" [Connectivity]. Objetivamente, esse modelo é analisado com base em uma estrutura para refletir acerca da educação musical. Para tanto, JORGENSEN (1980, p.25$30 ; 2011$, p.10) se vale de elaboração anterior na qual "propõe uma estrutura conceitual de várias facetas da educação musical" ${ }^{5}$. Essa estrutura comporta os seguintes elementos: música, ensino, aprendizagem, instrução, currículo e administração. Um alerta deve ser feito a respeito da necessidade de verificar qual o sentido que a autora concede a termos tão presentes no senso comum e fortemente vinculados ao contexto escolar e acadêmico, apenas um dos vários cenários onde aprendizagem e ensino de música podem acontecer "com integridade". Isso para que não se tome a compreensão desses elementos da citada estrutura de maneira limitada ao contexto escolar e acadêmico, compreensão que vai de encontro ao que Jorgensen defende como educação musical (ver citação do livro de 1997) ${ }^{6}$.

Em continuidade à explanação dessa filosofia da Educação Musical, a autora refere-se a cada par de metáfora-modelo como um quadro [picture] da educação musical. Esses quadros ou "tipos teóricos" "são apreciados comparativamente" já que, embora distintos, apresentam aspectos em comum. Mesmo o limite entre eles não é definido. De fato, eles se complementam, aponta a autora. "Tomá-los sozinhos não é suficiente". Entretanto, cada par é exposto separadamente com a finalidade de promover "a compreensão de seu foco conceitual e de seus limites" (JORGENSEN, 2011, p.10)

Visando "preservar a tensão entre cada metáfora e modelo", a autora "lista pares de metáforas associadas a modelos" baseada na sua própria experiência (JORGENSEN, 2011, p.9), cada qual compondo um capítulo conforme está indicado na nota de n. 4:

\author{
Metáfora e Modelo \\ Boutique e Consumo \\ Vila e Comunidade \\ Artista e Apreensão \\ Revolucionário e Transgressão \\ Indústria e Produção \\ Jardim e Crescimento \\ Terapeuta e Cura \\ Corte e Regra \\ Lar e informalidade \\ Guia e Pedagogia \\ Teia e Conectividade
}

Jorgensen refere-se a esse conjunto de quadros como uma galeria da qual ela é a curadora. Esses quadros são expressos por meio de "verbos e substantivos, sentidos estáticos e dinâmicos, processos e produtos, meios e fins". A sequência em que aparecem no livro não mantém qualquer ordem, "mas compreendem o mundo multifacetado e diverso da educação musical [...]" (JORGENSEN, 2011, p.12).

Dada a impossibilidade de comentar cada um dos pares de metáfora-modelo, concentro atenção no "quadro" "Teia" e "Conectividade".

$\mathrm{Na}$ exposição de cada "quadro", Jorgensen inicia descrevendo a metáfora, seguida de seu modelo sistematicamente exposto com base naqueles elementos da educação musical citados anteriormente. 
No caso de "Teia" e "Conectividade", a autora comenta tratar-se de imagens de "safra recente". Porém lembra que tais imagens já figuram na educação geral e na educação musical (tecnologia como o rádio promovendo a aprendizagem musical) pelo menos desde o início do século passado.

0 que a imagem de "teia" [web] evoca em Jorgensen? Com esse termo, a autora se refere a "um sistema complexo de elementos interconectados". Lembra a engenhosa, mortal, porém vital, teia das aranhas. Lembra também da internet - rede que é ao mesmo tempo virtual e completamente presente em nossas vidas concretas. A imagem que essas teias Ihe evocam são de "um sistema que é especificamente designado para seus propósitos (JORGENSEN, 2011, p.232). A autora se concentra na descrição das características da internet em termos sociais, tecnológicos e musicais, dizendo-se optar pelo caminho do meio entre o repúdio a essa tecnologia e a "tecnofilia". Ressalta, com isso, a necessidade de postura crítica tanto para perceber os "benefícios" da rede web quanto as "desvantagens que essa metáfora e seu modelo associado trazem para a educação musical" (JORGENSEN, 2011, p.236). Essa imagem figurativa da educação musical é seguida pela descrição mais objetiva do modelo a ela associado, "Conectividade".

As considerações conceituais referentes ao modelo de "Conectividade" iniciam-se pelo aspecto do ensino, apontando o papel do professor na "Conectividade": um guia dos estudantes para um "uso seguro e bem sucedido, crítico e avaliativo dasinformações disponíveis" na internet. Professores e estudantes compartilham interesses tanto "informais" quanto "formais" e trocam papéis quanto a quem ensina. No item "aprendizagem", além desses atores exercerem o papel de aprendizes no cenário, aprender ocorre tanto formalmente quanto informalmente e "os estudantes no modelo da conectividade ficam livres para seguir seus próprios interesses" (JORGENSEN, 2011, p.239). Ainda assim, a aprendizagem formal tem seu lugar assegurado na preparação dos estudantes para lidar com essas novas tecnologias. Análises desse tipo, apontando benefícios e limitações, são realizadas nos outros aspectos que Jorgensen considera na discussão da Educação Musical: instrução, currículo e administração. No caso da "instrução", são disponibilizadas "experiências audiovisuais e interativas"; professores e estudantes podem trabalhar conjuntamente. Mas corre-se o risco de materiais pré-formatados inibirem tanto a ação de estudantes quanto dos professores. 0 "currículo" nesse modelo tem, segundo a autora, "várias vantagens": "0 âmbito do estudo é ampliado"; "os materiais instrucionais podem ser constantemente atualizados"; "abordagens da matéria podem ser individualizadas". Entretanto, devese cuidar para algumas desvantagens como o currículo tornar-se um simples acúmulo de informações. Entender o elemento "administração" nesse modelo "Conectividade", elemento cujo sentido conferido por Jorgensen naquela mencionada estrutura para se pensar a Educação Musical se resume em "os meios e os fins de organizar o contexto no qual" a educação musical acontece (JORGENSEN, 2011, p.10), aponta que ela se beneficia das vantagens flexíveis dos sistemas virtuais, por exemplo, mas pode criar exclusões se todos não estiverem preparados para lidar com essas tecnologias digitais.

A autora finaliza o capítulo 13 que apresenta o quadro "Teia e Conectividade" discorrendo sobre as "vantagens e desvantagens musicais da conectividade", às quais ela se refere, respectivamente, como "lado claro e lado escuro" (JORGENSEN, 2011, p.244):

No lado claro, há possibilidades de ampliação e mudança de músicas que são menos limitadas no espaço e tempo, o ensino é colaborativo, o aprendizado virtual e por toda a vida, instrução intensificada, currículo ampliado e administração flexível. No lado escuro, as experiências acústicas e ao vivo de música podem ficar comprometidas, a autonomia do professor restrita, a aprendizagem ineficaz, a instrução forçada, e a aquisição de informação supervalorizada. Dadas essas possibilidades, resta-nos escolher os melhores aspectos e evitar os piores, pesando as oportunidades desses quadros para nossas vivências individuais e determinar como nos movermos para o futuro (JORGENSEN, 2011, p.250).

É possível identificar nessa proposta de pensar a Educação Musical a filosofia dialética característica da autora e sua convicção de que qualquer abordagem do real é sempre parcial e circunstancial, marcas que ficam reforçadas quando expõe que

$$
\begin{aligned}
& \text { esses quadros [compostos por pares de metáfora e modelo] } \\
& \text { expressam exemplos dos modos pelos quais a educação musical } \\
& \text { pode e deve funcionar; [...] eles têm o propósito modesto de } \\
& \text { abrir para outras possibilidades mais frutíferas de se entender } \\
& \text { as maneiras pelas quais as pessoas conhecem música [...] Eles } \\
& \text { ilustram as formas de contribuições dialética, dialógica e dinâmica } \\
& \text { de pensar sobre a educação musical e de praticá-la. Eles também } \\
& \text { sugerem meios pelos quais professores e outros interessados } \\
& \text { podem articular fenômenos disparatados, promovendo insights } \\
& \text { (JORGENSEN, 2011, p.12). }
\end{aligned}
$$

0 objetivo de Jorgensen com essa proposta de pensar a Educação Musical é "principalmente conceitual". A tarefa de testar o funcionamento prático desses pares ela deixa para outros pesquisadores.

Situada a autora, sua produção e exposta a proposta do livro resenhado, passo para algumas considerações críticas.

Um primeiro incômodo que pode sentir o leitor com relação ao livro ocorre já no sumário. Aquela listagem de pares de palavras ao mesmo tempo que atiça a curiosidade cria um sentimento de desconfiança, suspeita de talvez um tratamento aligeirado da Educação Musical. 0 enorme volume também pode ser desencorajador, mesmo sendo um quinto dele composto de notas. Entretanto, a progressiva aproximação com o conteúdo do texto transforma essa primeira percepção, pois o assunto é instigante, principalmente, imagino, para quem vem acompanhando a produção de Jorgensen.

0 primeiro parágrafo do prefácio, constituindose de uma série de perguntas, já mobiliza o leitor 
(perguntas citadas no início da resenha). A densidade da argumentação exige dedicação com leituras paralelas. Mas, essa densidade do texto, principalmente do capítulo 1, não encobre a clareza com que a autora expõe suas ideias e os procedimentos utilizados na construção dessa filosofia da Educação Musical.

Os capítulos que expõem os vários quadros apresentam 0 mesmo arcabouço narrativo, o que pode facilitar a leitura, mas que também se torna cansativa pela extensão do livro. Como não há a necessidade de seguir uma ordem de leitura, o leitor pode criar seu próprio percurso, o que dissiparia o citado cansaço. Outra característica da textualização é um didatismo, incluindo ao final de cada capítulo uma síntese do mesmo.

Ainda na ordem da narrativa dos capítulos que trazem os pares de metáfora e modelo, a estrutura que serve de base para a exposição dos modelos - "música, ensino, aprendizagem, instrução, currículo e administração" - cria um sentimento de inadequação dos mesmos pelo risco de uma leitura rápida levar à simples desqualificação do texto. Isso, mesmo com o cuidado de se atentar para o sentido que Jorgensen confere a eles, conforme exposto. Quem sabe a autora pudesse utilizar outros termos, apesar de que recorrer a esses, conferindo-Ihes outro sentido, tem seu valor de impacto no que tange ao repensar sobre significados arraigados.

Retomo a seguir duas das questões inicialmente levantadas por Jorgensen com a finalidade de, a partir delas, tecer alguns comentários críticos sobre sua proposta de pensar a Educação Musical.

"Qual seria a contribuição dessa análise para a prática da educação musical?" (JORGENSEN, 2011, p.xi).

Essa proposta para refletir e conduzir a ação pedagógica na educação musical colabora, a meu ver, com a ruptura de proposições unificadoras acerca do aprender e ensinar música que ainda persistem como referência conceitual e prática nesse campo de atuação. 0 que chama atenção na produção filosófica de Estelle R. Jorgensen é o investimento contínuo numa concepção núcleo de Educação Musical - aquela formulada no livro In search of Music Education (1997) e já citada-, ideia que é sistematicamente aprofundada e expandida nos anos seguintes. Nesse sentido The Pictures of Music Education nos parece uma proposta instigadora para pensarmos e agirmos no contexto contemporâneo da Educação Musical, onde as possibilidades e modalidades de conhecer música são incrivelmente amplas, diversas, discrepantes, conflitantes, ricas; tudo ao mesmo tempo.
Justamente, os desafios que a contemporaneidade coloca para a Educação Musical também encontram na filosofia dialética de Jorgensen alguns portos, pois ela admite "as multiplicidades e diversidades, as ambiguidades e incertezas, as inconsistências e oportunidades" (JORGENSEN, 2011, 269) que estão presentes nesses quadros e no cotidiano de educadores e pesquisadores da área.

Outra questão: "Por que não levar essa maneira de ação pedagógica e musical [quadros de metáforas e modelos] para pensar sobre a própria educação musical, de modo que abordagens usadas para explorar como as pessoas conhecem música sejam consistentes com a natureza da própria experiência musical?" (JORGENSEN, 2011, p.2).

Relacionei essa pergunta à compreensão que Jorgensen tem de que o pensar metaforicamente é parte das práticas musicais e pedagógico-musicais. Assim, a autora vislumbra no "exame sistemático" desse pensar metafórico, imaginativo, a possibilidade de conceitualizar a Educação Musical "músico-educacionalmente" (music educationally), mesmo mantendo a perspectiva interdisciplinar que caracteriza a construção desse campo de conhecimento.

Esse assunto, que é relevante aos que se dedicam à pesquisa em Educação Musical, diz respeito à autonomia ou não dessa área de conhecimento. Desde a menção da Pedagogia Musical como um dos campos investigativo dos estudos musicais por Guido Adler no final do século XIX (DUCKLES, 2012), a Educação Musical se vale de outras disciplinas para pensar a si própria. Ao longo do século XX áreas de referência predominaram de tempos em tempos: Psicologia, nas primeiras décadas, Sociologia (da Música) e Antropologia (Etnomusicologia) a partir dos anos 1970. Os estudos da Pedagogia sempre tiveram impacto na conceituação da área e, nas últimas décadas, os Estudos Culturais, a Semiótica, a Neurociência, entre outros, vieram somar-se aos interlocutores da Educação Musical. Sem dúvida, trata-se de uma área complexa de conhecimento, interseção de vários campos do saber (KRAEMER, 2000). Mas será que as maneiras como as pessoas conhecem música e a criam e praticam - porque aprenderam a fazê-lo (ARROYO, 2009) - não teria contribuição para com outros campos do saber? Tomando a defesa de John SHEPHERD e Peter WICKE (1997) sobre passar da mão única de direção que se desloca dos vários campos do conhecimento para as musicologias para a mão dupla de direção, com ênfase nas contribuições dos estudos musicais para outras áreas do saber, entendo que JORGENSEN vislumbra nessa filosofia de Educação Musical apresentada em The Pictures of Music Education a possibilidade de dupla direção na interface entre Educação Musical e outras disciplinas, partindo do pensar a Educação Musical a partir de suas propriedades. 


\section{Referências}

ARROYO, Margarete. Jovens, aprendizagem musical e novas práticas musicais. In: Congresso Anual da Associação Nacional de Pesquisa e Pós-Graduação em Música, XIX. Anais. Curitiba: ANPPOM, 2009. p.81-84.

BLACK, Max. Models and Metaphors: studies in Language and Philosophy. Ithaca, N.Y: Cornell University Press, 1962.

DUCKLES, Vincent, et al. Musicology. Grove Music Online. Oxford Music Online. Disponível em: http://www. oxfordmusiconline.com/subscriber/article/grove/music/46710pg1 (Acesso em 6 mai 2012).

JORGENSEN, Estelle R. The Art of Teaching Music. Bloomington: Indiana University Press, 2008.

. The artist and the pedagogy of hope. International Journal of Music Education, n. 27, p.136-50,1996.

. In search of music education. Urbana: University of Illinois Press, 1997.

. On the development of a Theory of Music Instruction", Psychology of Music, n.8, p.25-30, 1980.

. Transforming Music Education. Bloomington: Indiana University Press, 2003.

KRAEMER, Rudolf-Dieter. Dimensões e funções do conhecimento pedagógico-musical. Em Pauta, Porto Alegre, v. 11, n.16/17, p.49-73, 2000.

MCCARTHY, Mary; GOBLE, J.Scott. Music Education, Philosophy of. Grove Music Online. Oxford Music Online, 2011. Disponível em: http://www.oxfordmusiconline.com/subscriber/article/grove/music/A2093412 Acesso em: 11 ago 2011.

SHEPHERD, John; WICKE, Peter. Music and cultural theory. Cambridge: Polit Press, 1997.

\section{Notas}

No artigo The artist and the pedagogy of hope (JORGENSEN, 1996) a autora empreende um diálogo com as ideias de Paulo Freire.

2 Estele R. JORGENSEN esteve no Brasil em 2011, conferencista convidada da III Semana de Educação Musical do Instituto de Artes da UNESP, São Paulo, SP.

3 A diferença de grafia entre Educação Musical e educação musical remete, no primeiro caso, ao campo de conhecimento acadêmico-científico; no segundo, à prática que envolve aprender e ensinar música. Isso, exceto quando das citações.

4 Sumário do livro: 1. Metaphor and Model; 2. Boutique and Consumption; 3. Village and Community; 4. Artist and Apprenticeship; 5. Revolutionary and Transgression; 6. Factory and Production; 7. Garden and Growth; 8. Therapist and Healing; 9. Court and Rule; 10. Seashore and Energy; 11. Home and Informality; 12. Guide ad Pedagogy; 13. Web and Connectivity; 14. Picture and Practice.

5 Utilizo o termo 'estrutura' para não confundir o leitor, já que JORGENSEN denomina "modelo conceitual" aquele descrito no artigo de 1980 e de "modelo" esse que faz par com metáforas.

6 A autora retoma o sentido de cada um desses aspectos da educação musical no capítulo 1 deste livro resenhado. A título de ilustração do alerta feito, cito o sentido conferido pela autora ao termo "Aprendizagem" [Learning]: "trata-se de meios e fins pelos quais alguém vem a conhecer e transformar um assunto - no caso a música.[...](2011, p.11). Fica, portanto claro, que ele não se restringe ao universo escolar e acadêmico. 0 mesmo ocorre com os outros aspectos. Tanto esse termo como os outros que em uma primeira aproximação nos levariam apenas ao contextos escolar e acadêmico, são de fato muito mais abrangentes na descrição de JORGENSEN.

Margarete Arroyo é Graduada em Educação Artística: habilitação em Música pela Universidade de São Paulo e pós-graduada em Música - Educação Musical mestrado e doutorado pelo Programa de Pós-Graduação em Música da UFRGS. Atuou como docente e pesquisadora na Universidade Federal de Uberlândia no Curso de Graduação em Música de 1993 a 2010. Atua nessa mesma universidade como professora colaboradora no Programa de Pós-Gradação em Artes - Mestrado. Foi secretária da Associação Brasileira de Educação Musical entre 2001 e 2003. É membro do grupo Pesquisa e Formação em Educação Musical (CNPq) e líder do Grupo de Pesquisa sobre Aprendizagens Musicais na contemporaneidade (CNPq). Desde agosto de 2010 atua como docente e pesquisadora na Universidade Estadual Paulista Júlio de Mesquita Filho - UNESP, Instituto de Artes, Curso de Graduação em Educação Musical e Programa de Pós-Graduação em Música. Segue como linhas de pesquisa: Educação Musical, cultura e sociedade; Educação Musical formal e informal; Juventudes e músicas. 